\title{
Efficacy of class IV laser in the management of musculoskeletal pain: a systematic review
}

\author{
DOI: https://doi.org/10.5114/pq.2021.105882
}

\author{
Hernán Andrés de la Barra Ortiz, Sebastián Acevedo Cangas, Antonio Cumio Herrera, \\ Felipe Oñate García, Sebastián Velásquez Velásquez \\ Escuela de Kinesiología, Facultad de Ciencias de la Rehabilitación, Universidad Andrés Bello, Santiago, Chile
}

\section{Abstract}

Introduction. Musculoskeletal disorders (MSDs) are the main reason for disability in the world, causing pain and functional loss. Class IV laser is a recent treatment proposed for pain reduction in MSDs, although studies supporting its use and dosage are limited. The purpose of the paper was to describe the efficacy of class IV laser in the treatment of musculoskeletal pain. Methods. Randomized clinical trials were identified in the PubMed, Scopus, Web of Science, CINAHL, and ScienceDirect databases by a search on August 31, 2020. Three independent investigators reviewed article titles and abstracts for eligibility. Risk of bias and quality were evaluated with the Cochrane risk of bias tool and PEDro scale. Decreased pain was considered the main outcome; range of motion, strength, or disability were secondary outcomes.

Results. A total of 50 articles were obtained after eliminating duplicates, reduced to 7 after selection criteria application. MSDs included patellofemoral dysfunction $(n=1)$, epicondylitis $(n=1)$, osteoarthritis $(n=1)$, cervicalgia $(n=3)$, and lumbar radiculopathy $(n=1)$. The studies had a low risk of bias and a PEDro score greater than 7 . Pain reduction was observed at the end of laser treatments and in follow-up evaluations $(p<0.005)$; the decrease in disability favoured laser management $(p<0.005)$.

Conclusions. Class IV laser is effective in reducing pain and improving function in patients with MSDs. Further research is necessary to establish a consensus on the dosage and obtain more evidence in MSDs of non-articular origin.

Key words: lasers, phototherapy, class IV laser, musculoskeletal pain, musculoskeletal diseases, systematic review

\section{Introduction}

Musculoskeletal pain (MP) is understood as any pain associated with disorders that affect muscles, ligaments, bones, or joints, encompassing more than 150 diagnoses concerning the musculoskeletal system [1-3]. MP is usually described as penetrating, tense, and radiating, accompanied or not by hyperalgesia, classified as acute or chronic, depending on whether its duration is shorter or longer than 3 months $[4,5]$. Acute MP occurs in response to the stimulation of type III and IV nociceptors (afferent fibres $A \delta$ and $C$ ), which release neuropeptides peripherally, causing their sensitization and, potentially, hyperalgesia [4-6]. In turn, chronic MP corresponds to a sensory and emotional experience produced by alterations in the processing of central nervous system neurons that integrate unimodal and polymodal receptor afferents, which results in central sensitization. This situation is accompanied by alterations in antinociceptive mechanisms (inhibitors) and activation of pain-facilitating pathways, leading to generalized hypersensitivity, in addition to the activation of limbic system areas (pain neuromatrix theory); many authors classify it as non-plastic pain [6-9].

Musculoskeletal disorders (MSDs) are among the main causes of disability in the world, standing out as the most common problems of osteoarthritis, low back pain, neck pain, tendinopathies, fibromyalgia, and myofascial pain, which are accompanied by movement limitations, decreased strength, loss of dexterity and functional capacity, and compromised life quality; also, they translate into increased demands for health care [2-10]. Approximately $35-65 \%$ of people have experienced some MSDs in their lifetime, and the persistence of symptoms can accentuate the physical, psychological, and socioeconomic impacts [11-13].

Laser therapy is a physical resource used to promote tissue repair, wound healing, and pain management in patients with MSDs [11-14]. This electromagnetic radiation includes wavelengths located in the visible red or infrared spectrum, and its production is based on the phenomenon of stimulated emission of radiation, that is, photonic emission when atoms are excited by a source of electrical energy $[15,16]$. Photons are absorbed into tissues by chromophore molecules, sensitive to specific wavelength bands. For example, water molecules are long wavelength absorbers, and haemoglobin and melanin are short wavelength absorbers. The absorption of radiation increases the atomic and molecular kinetic energy, generating biological effects [15-19]. Therapeutic laser radiation is commonly produced from gaseous mixtures of $\mathrm{HeNe}$ (wavelength: $632.8 \mathrm{~nm}$ ) or semiconductor diodes of AsGa or AsAIGa (wavelength: 630-950 nm) [15-20].

Laser depth will depend on the wavelength, wave dispersion, power, and tissue absorption coefficient. Dispersion increases when working with short wavelengths, so red lasers will present less penetration [15, 16, 20]. Therapeutic wavelengths are concentrated between 620 and $1200 \mathrm{~nm}$ (therapeutic window), and lengths outside this range will be concentrated in the skin, with limited depth [15, 21].

Lasers have been classified into low-power devices (class Illb or low intensity laser therapy [LILT]) and high-power devices (class IV or high intensity laser therapy [HILT]), depending on whether the emission power is smaller or greater than $500 \mathrm{~mW}(0.5 \mathrm{~W})$. LILTs present athermic effects and are

Correspondence address: Hernán Andrés de la Barra Ortiz, Universidad Andrés Bello, Facultad de Ciencias de la Rehabilitación, Escuela de Kinesiología, Avenida Fernández Concha Nㅜ700, Las Condes, Región Metropolitana, Chile, Postal Code: 7591538, e-mail: hdelabarra@unab.cl 
recognized for their photobiomodulatory results since they can favour or inhibit biological processes depending on the energy dose delivered, in accordance with the Arndt-Schulz law, with an average depth of 3-4 cm [16, 17, 21, 22]. In turn, class IV devices are characterized by deep photothermic and photochemical effects, presenting a more diffuse and less concentrated energy emission, which generates the slowest absorption by chromophores, reaching average depths of $10-12 \mathrm{~cm}[20,21]$.

The analgesic effects of class IV laser have been supported by its photochemical effects, highlighting the activation of enzymes of the respiratory chain and synthesis of ATP, DNA, and RNA. This would be accompanied by physiological effects such as increased metabolism and microcirculation, decreased nociceptive nerve conduction, and the release of beta-endorphins. Effects such as decreased inflammation, collagen genesis, stimulation of immune processes, and nerve regeneration have also been documented $[16,17$, 19-25].

The World Association for Laser Therapy has proposed dosage recommendations for LILT in various musculoskeletal conditions; however, recommendations for class IV laser have not been documented [26]. It has been suggested that HILT could decrease MP in conditions such as rheumatoid arthritis, osteoarthritis, carpal tunnel syndrome, fibromyalgia, painful shoulder, trigeminal neuralgia, postoperative pain, and knee pain, and that it would be advantageous owing to its photothermal effects and more depth [23-30].

Although class IV laser has been recognized in recent years as a therapeutic alternative for MP management, there is a lack of research to support its effectiveness. Thus, the objective of this systematic review was to investigate the scientific evidence of the last decade regarding the efficacy of class IV laser in the treatment of MP.

\section{Subjects and methods}

This systematic review adheres to the Preferred Reporting Items for Systematic Reviews and Meta-Analyses (PRISMA) statement [31]. This research was uploaded electronically to the International Prospective Register of Systematic Reviews (PROSPERO) of the National Institute for Health Research (https://www.crd.york.ac.uk/prospero) and obtained the identification code of CRD42020205701.

\section{Search strategy}

A systematic review was carried out considering the electronic databases of PubMed, Scopus, Web of Science, CINAHL, and ScienceDirect, with the last update on August 31, 2020. The Physiotherapy Evidence Database (PEDro) scale was applied. On the basis of the PICO (patient, intervention, comparison, outcome) formula, a search algorithm was developed to evaluate the effects of class IV laser in reducing pain (acute or chronic) in patients with MSDs [32]. The following keywords (MeSH terms) were used: 'Lasers,' 'Phototherapy,' 'High Intensity Laser Therapy,' 'Class IV laser,' 'Musculoskeletal Pain,' 'Musculoskeletal Diseases,' 'Myofascial Pain Syndromes,' 'Myalgia,' 'Trigger Points,' and 'Arthralgia,' with the Boolean connectors 'OR' and 'AND'. The following algorithm was obtained: ((((“Lasers”[MeSH Terms]) OR ("Phototherapy"[MeSH Terms])) OR ("High Intensity Laser Therapy"))) OR ("Class IV laser")))) AND (((((("Musculoskeletal Pain"[MeSHTerms]) OR ("Musculoskeletal Diseases"[MeSH Terms])) OR ("Myofascial Pain Syndromes"[MeSH Terms]))) OR ("Myalgia"[MeSH Terms])))) OR ("Trigger Points"[MeSH Terms]))))) OR (“Arthralgia"[MeSH Terms])))))).
The outcomes of the search with the keywords proposed were downloaded for each database (nbib, ris, or ciw formats). The files were uploaded and analysed with the Rayyan tool, developed for the preliminary selection of abstracts and titles of articles (https://rayyan.qcri.org) [33].

Three independent researchers (S.A., A.C., and S.V.) analysed the titles and abstracts of the articles on the basis of the selection criteria, classifying them in the categories: 'included,' 'possible,' and 'excluded'. In addition, studies references were examined, with extracting and reviewing their country of origin, author, affiliated institutions, and enrolment periods to identify and exclude duplicate publications. Articles in the 'possible' category were reviewed by the research team to be or not to be included in the final count. Each author recorded exclusion reasons of papers. Articles with incomplete abstracts were discarded from the analysis. The main outcome variable was reduction of pain intensity in MSDs treated with class IV laser, while range of motion or changes in muscle strength and/or improvement in quality of life or disability for the treated MSDs were considered as secondary outcomes. For the included articles, the study objective, PEDro scale score, participants' demographic data, declaration of conflicts of interest, follow-up period, evaluation time, treatment protocol, class IV laser dose applied, and main and secondary outcomes were analysed [34, 35].

The risk of bias in the articles was assessed with the evaluation tool proposed by the Cochrane Collaboration, considering the following criteria [36, 37]; (1) random selection of participants (selection bias), (2) allocation concealment (selection bias), (3) participants and staff blinding (performance bias), (4) results of measurements blinding (detection bias), (5) results with incomplete data (attrition bias), (6) selective reporting or reporting (reporting bias), and (7) other sources of bias. The tool classifies the risk of bias as high, low, or unclear. Poor methodological quality trials were those with 3 or more high risks of bias [36].

\section{Selection criteria}

The inclusion criteria were as follows: (1) randomized clinical trials (RCT) or clinical controlled trials; (2) studies in humans; (3) participants older than 18 years; (4) articles published in the previous 10 years; (5) articles in the English language; (6) studies using class IV laser or HILT alone or with another intervention as pain management in MSDs; and (7) comparison with another treatment, sham application, or placebo. We excluded (i) case reports, systematic reviews, meta-analyses, and literature reviews; (ii) animal or in vitro studies; (iii) class IV laser treatments in non-musculoskeletal conditions; (iv) pain resulting from neurological conditions (e.g. hemiplegia, spinal cord injury, diabetic neuralgia); and (v) studies whit incomplete abstracts.

\section{Quality of articles and risk of bias}

Quality of the elected articles was evaluated with the PEDro scale (kappa coefficients between 50 and 79 for ratings consensus generated by groups of 2 or 3 evaluators) $[34,35]$. Each investigator performed an independent assessment, and any disagreement was subsequently discussed in a team until consensus was reached. RCTs with scores $\leq 5$ in the PEDro scale were rated as low quality, while those scored $\geq 6$ were considered as high quality (Table 1).

\section{Ethical approval}

The conducted research is not related to either human or animal use. 
Table 1. PEDro scale score of the analysed studies [34, 35]

\begin{tabular}{|c|c|c|c|c|c|c|c|c|c|c|c|c|c|}
\hline \multirow{2}{*}{$\begin{array}{c}\text { Clinical trial } \\
\text { number }\end{array}$} & \multirow{2}{*}{ Author, year of publication } & \multicolumn{11}{|c|}{ PEDro scale criteria* $[34,35]$} & \multirow{2}{*}{ Total score } \\
\hline & & 1 & 2 & 3 & 4 & 5 & 6 & 7 & 8 & 9 & 10 & 11 & \\
\hline 1 & Nouri et al. (2019) [38] & 1 & 1 & 1 & 1 & 1 & 0 & 0 & 1 & 1 & 1 & 1 & 9 \\
\hline 2 & Roberts et al. (2013) [39] & 1 & 1 & 1 & 1 & 1 & 1 & 0 & 1 & 1 & 1 & 1 & 10 \\
\hline 3 & Angelova and Ilieva (2016) [40] & 1 & 1 & 1 & 1 & 1 & 0 & 0 & 1 & 1 & 1 & 1 & 9 \\
\hline 4 & Dundar et al. (2015) [41] & 1 & 1 & 0 & 1 & 1 & 0 & 0 & 1 & 1 & 1 & 1 & 8 \\
\hline 5 & Venosa et al. (2019) [42] & 1 & 1 & 0 & 1 & 1 & 0 & 0 & 1 & 1 & 1 & 1 & 8 \\
\hline 6 & Yilmaz et al. (2020) [43] & 1 & 1 & 1 & 1 & 1 & 0 & 0 & 1 & 1 & 1 & 1 & 9 \\
\hline 7 & Kolu et al. (2018) [44] & 1 & 1 & 1 & 1 & 1 & 0 & 0 & 1 & 1 & 1 & 1 & 9 \\
\hline
\end{tabular}

* PEDro (Physiotherapy Evidence Database) scale criteria:

(1) The selection criteria were specified.

(2) Subjects were randomized into groups (in a crossover study, subjects were randomized as they received treatments).

(3) The assignment was hidden.

(4) The groups were similar at the beginning in relation to the most important prognostic indicators.

(5) All subjects were blinded.

(6) All therapists who administered the therapy were blinded.

(7) All assessors who measured at least one key outcome were blinded.

(8) Measures of at least one of the key outcomes were obtained from more than $85 \%$ of the subjects initially assigned to the groups.

(9) Results were presented for all subjects who received treatment or were assigned to the control group, or, when this could not be the case, data for at least one key outcome were analysed by 'intention to treat'.

(10) Results of statistical comparisons between groups were reported for at least one key outcome.

(11) The study provides point and variability measures for at least one key outcome.

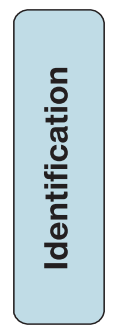

Records identified through database searching

PubMed $(n=70)$; Scopus $(n=191)$; Web of Science $(n=22)$; CINAHL $(n=4)$; ScienceDirect $(n=1682)$ $N=1969$

\section{ELIGIBILITY CRITERIA}

- Randomized

or controlled clinical trials

- Human studies

- Participants over

18 years of age

- Articles published

in the previous 10 years (2010-2020)

- Articles in the English

language

- Use of HILT

(class IV laser) alone

or another intervention

as pain treatment

in musculoskeletal conditions

- Comparison with another treatment, sham application, or placebo
Records after duplicates removed $(n=260)$
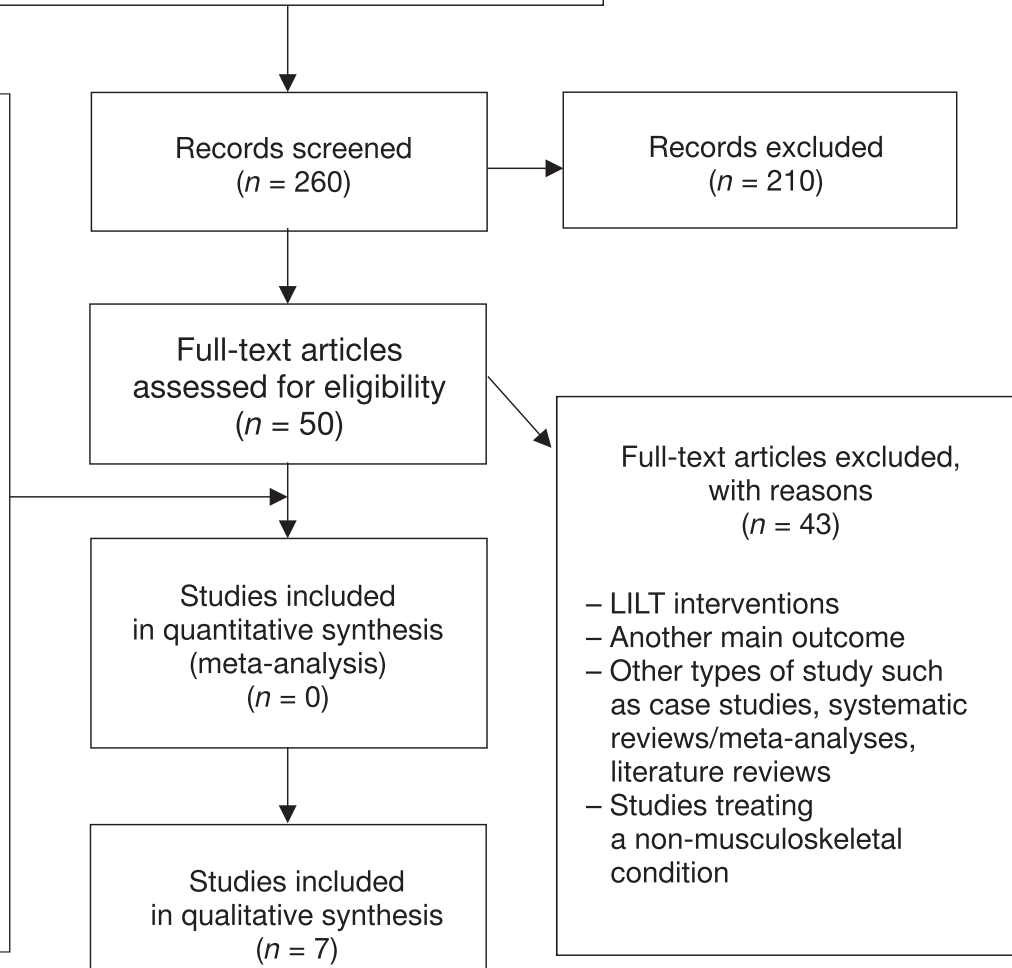

Figure 1. Flowchart of studies included in the review in accordance with the PRISMA 2009 guidelines [31, 37] 


\section{Results}

The initial search strategy yielded a total of 1969 articles from the selected databases (PubMed, $n=70$; Scopus, $n=$ 191; Web of Science, $n=22$; CINAHL, $n=4$; ScienceDirect, $n=1682)$. Subsequently, when duplicates were eliminated with the use of the Rayyan detection tool, a total of 260 articles were obtained. The main reasons for exclusion were LILT treatments, systematic reviews and meta-analyses, literature reviews, another main outcome, lack of a comparison group, animal or in vitro studies, and other health conditions. After reviewing titles and abstracts, a total of 50 articles were obtained between 'possible' and 'included'. The selection criteria were applied, and consensus was reached for the 'possible' and 'included' articles, discarding 43, and obtaining 7 articles for analysis. As causes of exclusion, interventions with LILT $(n=16)$, another main outcome $(n=14)$, another type of study $(n=8)$, and non-musculoskeletal conditions $(n=4)$ stand out. Figure 1 shows the PRISMA flow chart with a summary of the selection results, while Figure 2 presents the risk of bias of the selected articles. The results imply that none of the trials had more than 3 high risks of bias; therefore, the selected studies were classified as good quality [36, 37].

The reported MSDs included patellofemoral pain syndrome $(n=1)$ [38], epicondylitis $(n=1)$ [39], knee osteoarthritis pain $(n=1)$ [40], myofascial pain of the upper trapezius muscle $(n=1)$ [41], cervical spondylosis pain $(n=1)$
[42], neck pain due to herniated disc $(n=1)$ [43], and radicular low back pain [44]. Table 2 summarizes the characteristics of the selected articles. The 7 selected articles showed a PEDro score greater than 6 , with an average score of 9 points, so the selected RCTs were attributed good internal validity. In turn, Table 3 indicates the parameters used for class IV laser. The results show the use of infrared lasers in the 7 articles: wavelength $1064 \mathrm{~nm}$ [38, 40-44] and mixed wavelength of $980 / 810 \mathrm{~nm}$ [39]. In most of the studies, pulsatile emission was applied, except for the studies by Roberts et al. [39] and Kolu et al. [44], who reported $100 \%$ delivery cycles. Furthermore, treatment times of 2-5 minutes were generally observed, except for the studies by Venosa et al. [42] and Yilmaz et al. [43], in which 15 and 30 minutes were proposed. In relation to the reported fluence (energy density), various values can be seen, ranging from $360 \mathrm{~mJ} / \mathrm{cm}^{2}$ to $1000 \mathrm{~J} / \mathrm{cm}^{2}$, coinciding only with the investigations by Nouri et al. [38] and Kolu et al. [44]. The studies generally indicate applications between 5 and 10 sessions, except for the study by Yilmaz et al. [43], reporting a total of 20 treatment sessions [43].

Considering pain intensity as the main outcome, the most frequently used evaluation instrument was the visual analogue scale (VAS) [45, 46], applied to assess pain at rest, on palpation, and in motion; additionally, it was used in some studies for nocturnal pain assessment in myofascial syndrome and lumbar radiculopathy [41, 44]. Angelova and llieva [40] incorporated algometry in conjunction with VAS

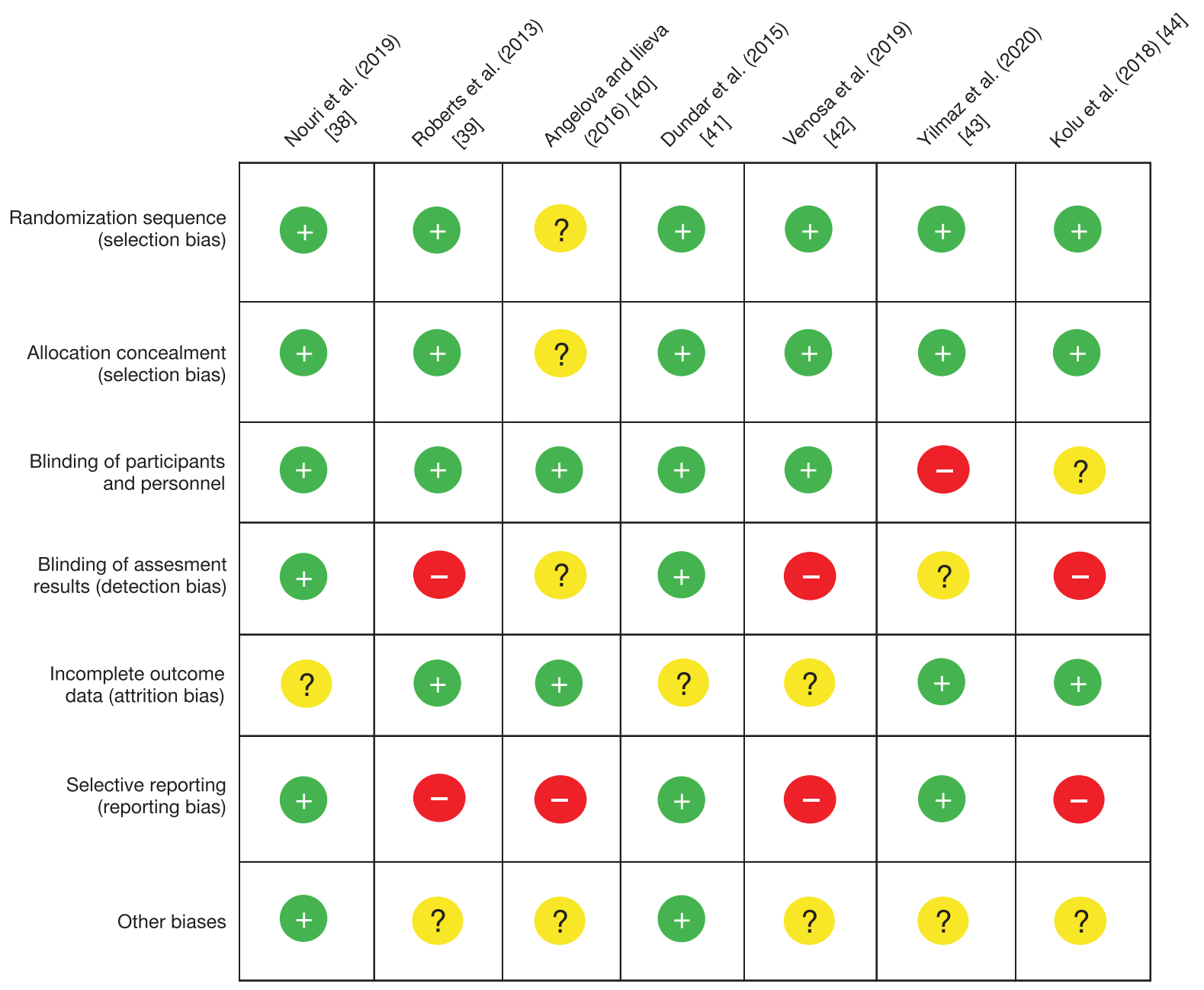

The '+' sign means low risk of bias, '-' means high risk of bias, '?' means unclear risk of bias. Trials involving 3 or more high risks of bias were considered as poor methodological quality. 


\begin{tabular}{|c|c|c|c|}
\hline 高咅 & F & 홍 & F \\
\hline 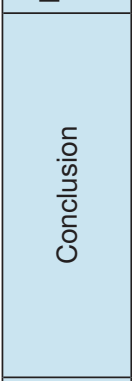 & 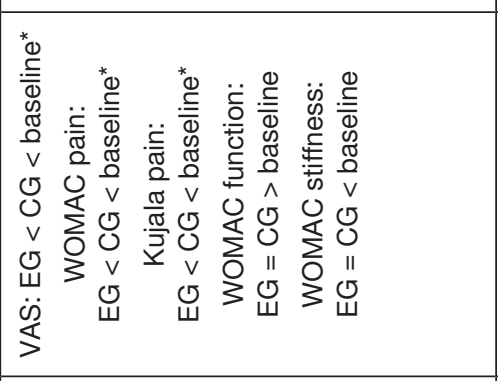 & 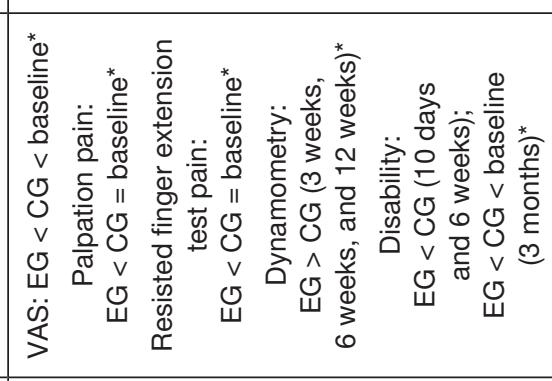 & 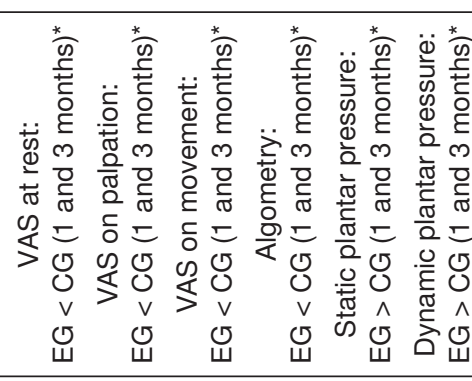 \\
\hline 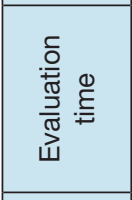 & 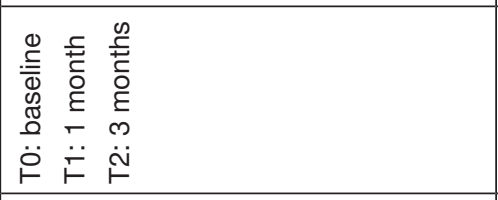 & 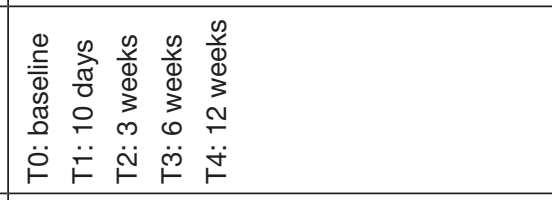 & 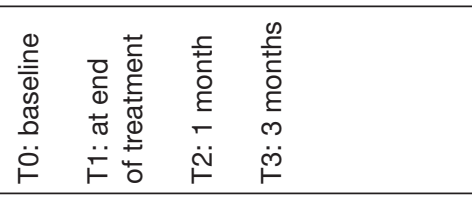 \\
\hline 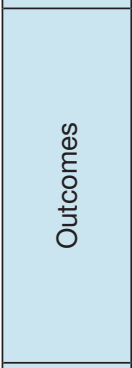 & 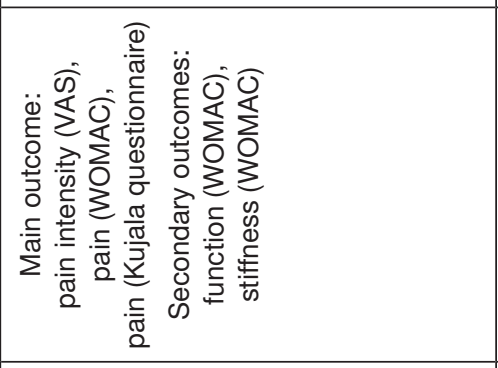 & 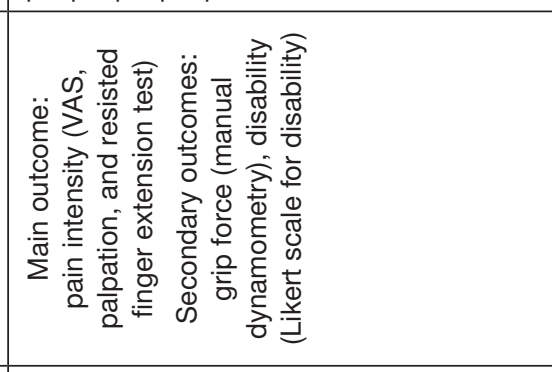 & 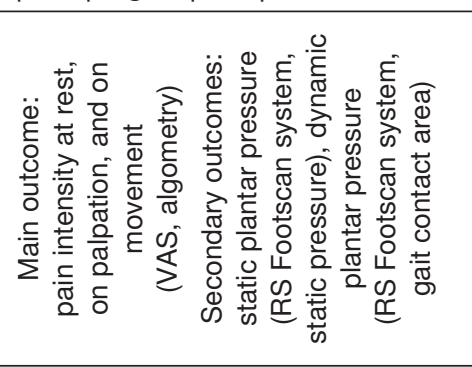 \\
\hline 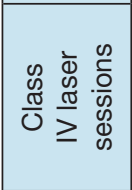 & 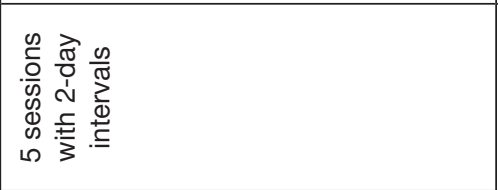 & 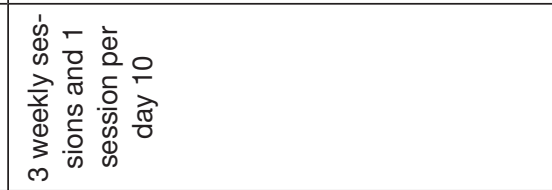 & 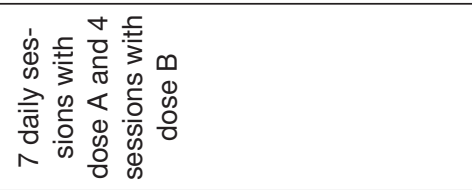 \\
\hline 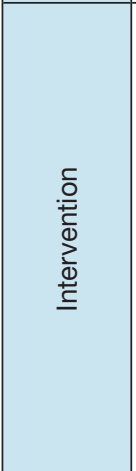 & 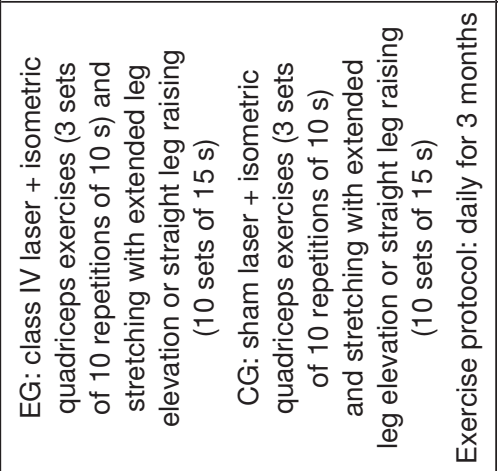 & 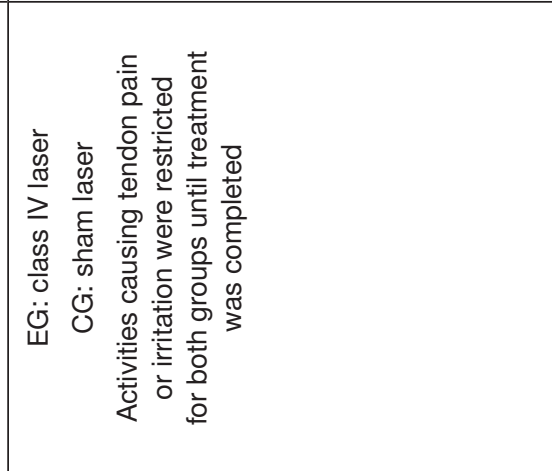 & 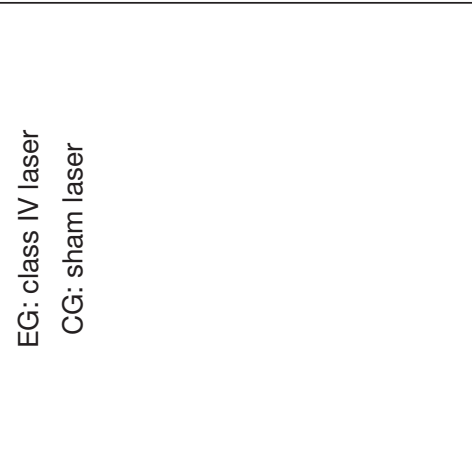 \\
\hline 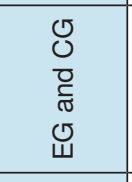 & 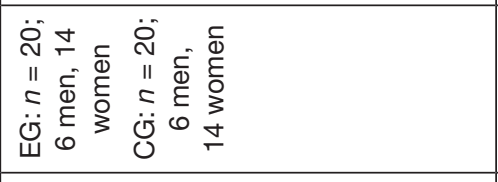 & 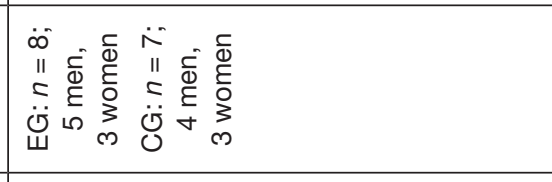 & 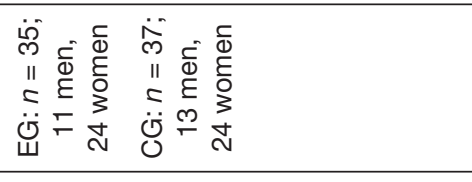 \\
\hline 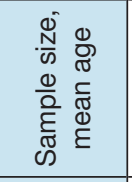 & 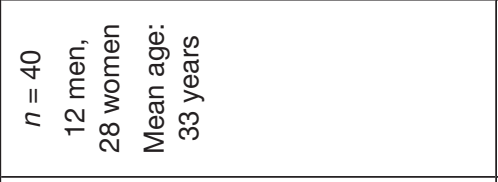 & 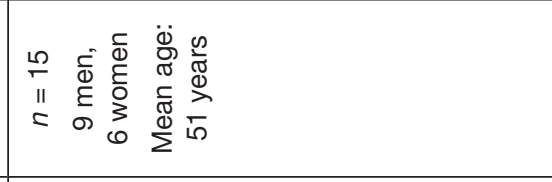 & 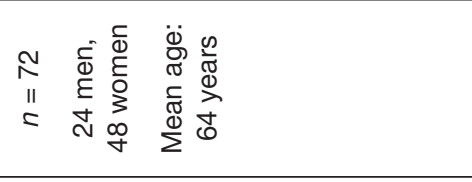 \\
\hline$\sum_{2}^{0}+\frac{\vec{z}}{\vec{n}}$ & 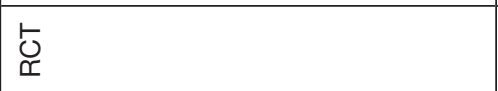 & 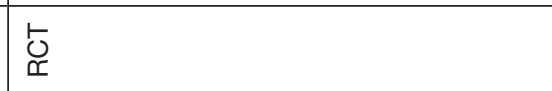 & $\underset{\sim}{\mathfrak{O}}$ \\
\hline 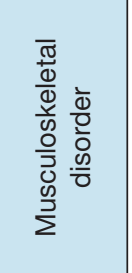 & 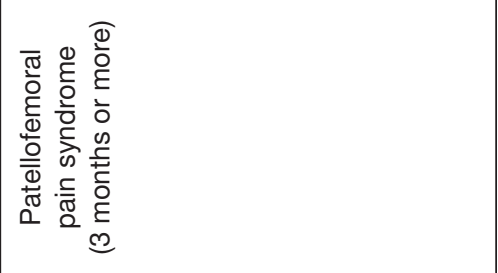 & 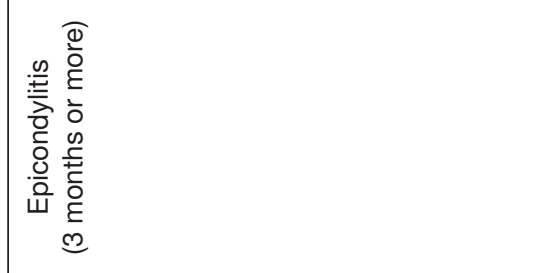 & 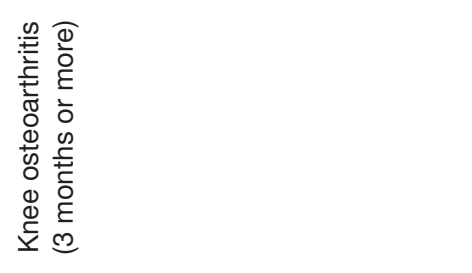 \\
\hline 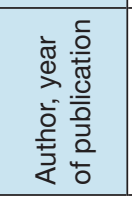 & 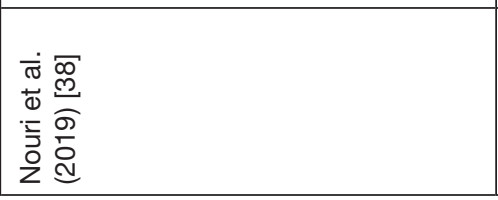 & 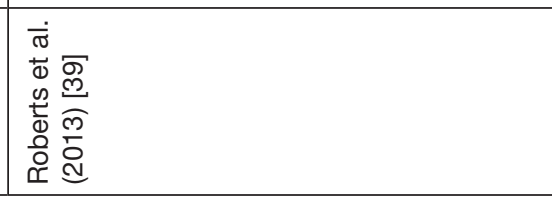 & 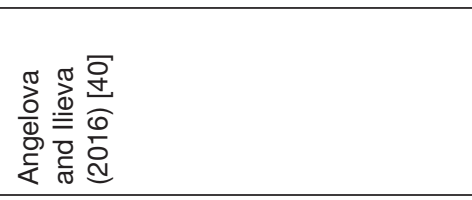 \\
\hline
\end{tabular}




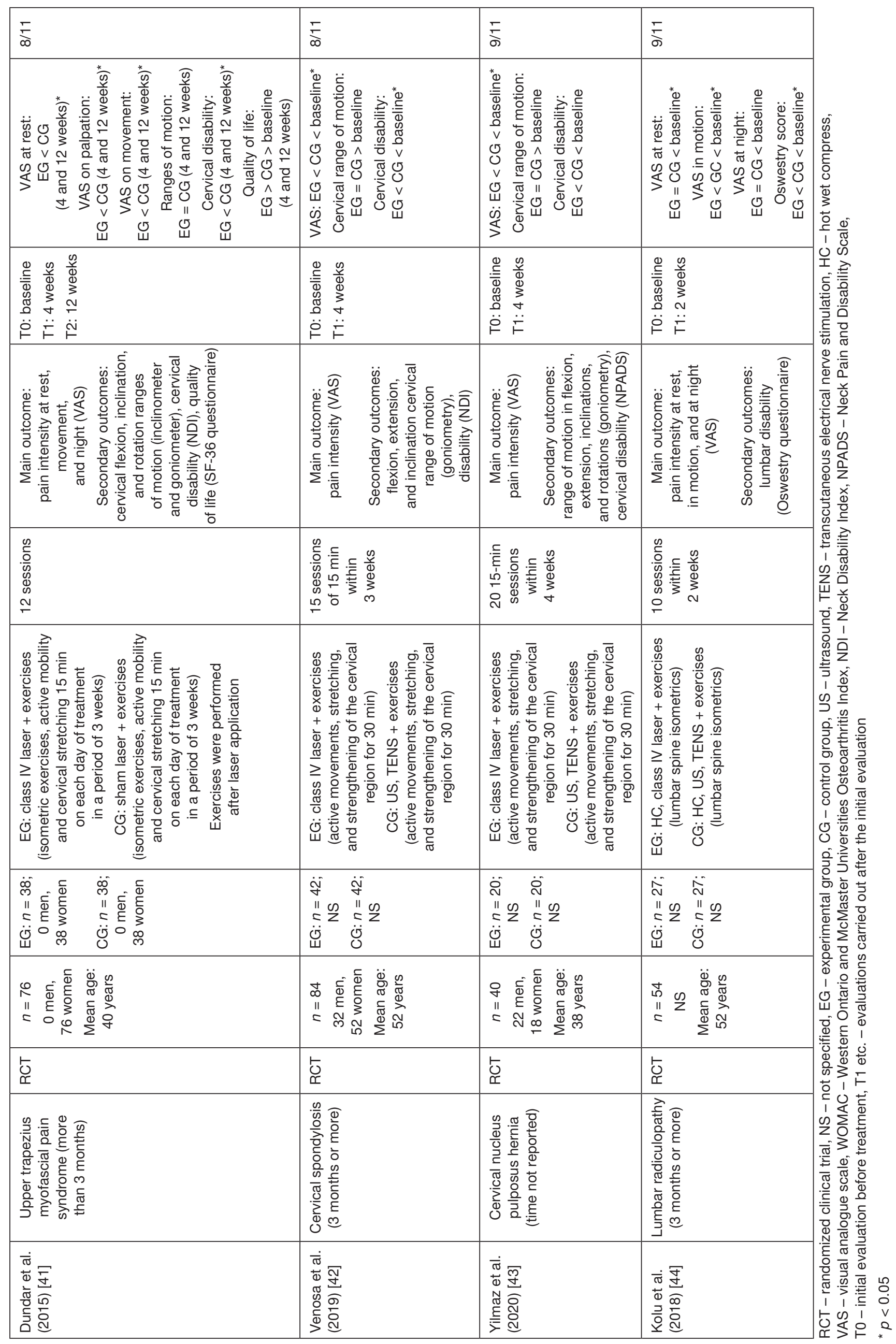


Table 3. Types of lasers used in the included studies

\begin{tabular}{|c|c|c|c|}
\hline Author, year of publication & Musculoskeletal disorder & Laser parameters & Class IV laser sessions \\
\hline $\begin{array}{l}\text { Nouri et al. } \\
\text { (2019) [38] }\end{array}$ & $\begin{array}{l}\text { Patellofemoral pain syndrome } \\
\text { (3 months or more) }\end{array}$ & $\begin{array}{l}\text { Wavelength: } 1064 \mathrm{~nm} \\
\text { Power: } 10 \mathrm{~W} \\
\text { Duty cycle: } 25 \% \\
\text { Energy density: } 120 \mathrm{~J} / \mathrm{cm}^{2} \\
\text { Treatment time: } 120 \mathrm{~s} \\
\text { Non-contact application }(2 \mathrm{~cm})\end{array}$ & $\begin{array}{l}5 \text { sessions } \\
\text { with } 2 \text {-day intervals }\end{array}$ \\
\hline $\begin{array}{l}\text { Roberts et al. } \\
(2013) \text { [39] }\end{array}$ & $\begin{array}{c}\text { Epicondylitis } \\
\text { (3 months or more) }\end{array}$ & $\begin{array}{l}\text { Wavelength: } 980 / 810 \mathrm{~nm} \text { mix ( } 80: 20 \text { radius) } \\
\text { Power: } 10 \mathrm{~W} \\
\text { Duty cycle: } 100 \% \\
\text { Energy density: } 6.6 \pm 1.3 \mathrm{~J} / \mathrm{cm}^{2} \\
\text { Treatment time: } 300 \mathrm{~s} \\
\text { Non-contact application: } 2.5 \mathrm{~cm}\end{array}$ & $\begin{array}{l}3 \text { weekly sessions } \\
\text { and } 1 \text { session per day } 10\end{array}$ \\
\hline $\begin{array}{l}\text { Angelova and Ilieva } \\
\text { (2016) [40] }\end{array}$ & $\begin{array}{l}\text { Knee osteoarthritis } \\
\text { ( } 3 \text { months or more) }\end{array}$ & $\begin{array}{l}\text { Dose A: } \\
\text { Wavelength: } 1064 \mathrm{~nm} \\
\text { Energy density: } 12 \mathrm{~J} / \mathrm{cm}^{2}(\text { energy } 300 \mathrm{~J} \\
\left.\text { and treatment area } 25 \mathrm{~cm}^{2}\right) \\
\text { Pulse frequency: } 25 \mathrm{~Hz} \\
\text { Treatment time: } 120 \mathrm{~s} \\
\text { Non-contact application } \\
\text { Dose B: } \\
\text { Wavelength: } 1064 \mathrm{~nm} \\
120 \mathrm{~J} / \mathrm{cm}^{2} \text { (energy } 3000 \mathrm{~J} \text { and treatment area } 25 \mathrm{~cm}^{2} \text { ) } \\
\text { Pulse frequency: } 25 \mathrm{~Hz} \\
\text { Treatment time: } 600 \mathrm{~s} \\
\text { Non-contact application }\end{array}$ & $\begin{array}{l}7 \text { daily sessions } \\
\text { with dose } A \\
\text { and } 4 \text { sessions } \\
\text { with dose B }\end{array}$ \\
\hline $\begin{array}{l}\text { Dundar et al. } \\
\text { (2015) [41] }\end{array}$ & $\begin{array}{c}\text { Upper trapezius myofascial } \\
\text { pain syndrome } \\
\text { (more than } 3 \text { months) }\end{array}$ & $\begin{array}{l}\text { First phase (6 points treated, bilateral application) } \\
\text { Wavelength: } 1064 \mathrm{~nm} \\
\text { Pulsed emission } \\
\text { Power: } 3 \mathrm{~kW} \\
\text { Duty cycle: } 0.1 \% \\
\text { Frequency: } 10-40 \mathrm{~Hz} \\
\text { Energy density: application in } 3 \text { subphases } \\
360 \mathrm{~mJ} / \mathrm{cm}^{2}(166.7 \mathrm{~J}), 410 \mathrm{~mJ} / \mathrm{cm}^{2}(166.8 \mathrm{~J}) \text {, } \\
\text { and } 510 \mathrm{~mJ}^{2} \mathrm{~cm}^{2}(166.5 \mathrm{~J}) \\
\text { Spacer application (perpendicular probe) } \\
\text { Second phase (6 points covered, bilateral application) } \\
\text { Wavelength: } 1064 \mathrm{~nm} \\
\text { Pulsed emission } \\
\text { Power: } 3 \mathrm{~kW} \\
\text { Duty cycle: } 0.1 \% \\
\text { Frequency: } 10-40 \mathrm{~Hz} \\
\text { Energy density: } 610 \mathrm{~mJ} / \mathrm{cm}^{2}(60 \mathrm{~J}) \\
\text { Treatment time: } 6 \mathrm{~s} \mathrm{per} \mathrm{point} \\
\text { Spacer application (perpendicular probe) } \\
\text { Third phase } \\
\text { Wavelength: } 1064 \mathrm{~nm} \\
\text { Pulsed emission } \\
\text { Power: } 3 \mathrm{~kW} \\
\text { Duty cycle: } 0.1 \% \\
\text { Frequency: } 10-40 \mathrm{~Hz} \\
\text { Energy density: application in subphases } \\
360 \text { mJ/cm² }(166.7 \mathrm{~J}), 410 \mathrm{~mJ} / \mathrm{cm}^{2}(166.8 \mathrm{~J}) \text {, } \\
\text { and } 510 \mathrm{~mJ} / \mathrm{cm}^{2}(166.5 \mathrm{~J}) \text { for a total energy of } 500 \mathrm{~J} \\
\text { Treatment time: } 60 \mathrm{~s}\left(100 \mathrm{~cm}^{2} \text { area) }\right. \\
\text { Manual scan application }\end{array}$ & 12 sessions \\
\hline $\begin{array}{l}\text { Venosa et al. } \\
(2019)[42]\end{array}$ & $\begin{array}{l}\text { Cervical spondylosis } \\
\text { (3 months or more) }\end{array}$ & $\begin{array}{l}\text { Wavelength: } 1064 \mathrm{~nm} \\
\text { Power: } 3 \mathrm{~kW} \\
\text { Duty cycle: } 0.1 \% \\
\text { Pulse frequency: } 10-40 \mathrm{~Hz} \\
\text { Energy density: first phase } 1000 \mathrm{~J} / \mathrm{cm}^{2} \text {, } \\
\text { second phase application for } 8 \text { pain points } 200 \mathrm{~J} \text {, } \\
\text { third phase } 1000 \mathrm{~J} / \mathrm{cm}^{2} \\
\text { Treatment time: } 30 \mathrm{~min} \\
\text { Non-contact application }(2 \mathrm{~cm}): \text { phase } 1 \text { and } 3 \\
\text { manual scanning and phase } 2 \text { static application }\end{array}$ & $\begin{array}{l}15 \text { sessions of } 15 \text { min } \\
\text { within } 3 \text { weeks }\end{array}$ \\
\hline $\begin{array}{l}\text { Yilmaz et al. } \\
\text { (2020) [43] }\end{array}$ & $\begin{array}{l}\text { Cervical nucleus } \\
\text { pulposus hernia } \\
\text { (time not reported) }\end{array}$ & $\begin{array}{l}\text { Wavelength: } 1064 \mathrm{~nm} \\
\text { Power: } 8 \mathrm{~W} \\
\text { Pulse frequency: } 25 \mathrm{~Hz} \\
\text { Energy density } 5 \mathrm{~J} / \mathrm{cm}^{2} \text { (area } 25 \mathrm{~cm}^{2} \text { ) } \\
\text { Treatment time } 15 \mathrm{~min} \\
\text { Contact application in the form of a scan } \\
\text { over the paraspinal muscles }\end{array}$ & $\begin{array}{l}2015-\text { min sessions } \\
\text { within } 4 \text { weeks }\end{array}$ \\
\hline $\begin{array}{l}\text { Kolu et al. } \\
(2018)[44]\end{array}$ & $\begin{array}{l}\text { Lumbar radiculopathy } \\
\text { ( } 3 \text { months or more) }\end{array}$ & $\begin{array}{l}\text { Wavelength: } 1064 \mathrm{~nm} \\
\text { Power: } 7 \mathrm{~W} \\
\text { Duty cycle: } 100 \% \\
\left.\text { Energy density: } 120 \mathrm{~J} / \mathrm{cm}^{2} \text { (area } 25 \mathrm{~cm}^{2}\right) \\
\text { Treatment time: } 360 \mathrm{~s} \\
\text { Non-contact application }(2 \mathrm{~cm})\end{array}$ & $\begin{array}{c}10 \text { sessions } \\
\text { within } 2 \text { weeks }\end{array}$ \\
\hline
\end{tabular}


for pain measurement. All the studies show a decrease in pain at rest and movement in the experimental and control groups in relation to the initial evaluation (T0 or baseline), the change being greater in favour of the experimental group, with the exception reported by Kolu et al. [44], where the decrease in pain at rest did not exhibit statistically significant differences between groups (experimental group, $p=0.283$; control group, $p=0.486$ ).

Range of motion as a secondary outcome was reported only for cervical MSDs, evaluated with goniometry and an inclinometer [41-43]. An improvement in the range of motion for both groups compared with TO was observed in all the studies, although without statistically significant differences between groups in the evaluation of the movements of flexion, extension, inclinations, and cervical rotations (Dundar et al. [41], $p$-value of 0.378-0.911; Venosa et al. [42], $p>0.05$; Yilmaz et al. [43], $p$-value of 0.282-0.898).

The assessment of muscle strength is only reported by Roberts et al. [39], who applied manual dynamometry as an indicator to measure grip pain in patients with epicondylitis. The study indicates a statistically significant difference in grip pain in favour of the experimental group at 10 days, as well as 3,6 , and 12 weeks after treatment $(p<0.001)$.

An article highlights the static and dynamic foot barometric assessment with the RS Footscan system in patients with knee osteoarthritis [40]. The study reported statistically significant differences for the static plantar contact variable at 7 days $(p<0.0001), 1$ month $(p=0.016)$, and 3 months $(p<0.0001)$, in favour of the control group. An improvement in plantar contact during walking was also observed for the experimental group at 7 days $(p<0.0001), 1$ month $(p<$ $0.0001)$, and 3 months $(p<0.0001)$ [40].

For disability assessment, specific functional questionnaires for each reported MSD were applied, including the Western Ontario and McMaster Universities Osteoarthritis Index (WOMAC) and the Kujala questionnaire [38], Likert scale for disability [39], Neck Disability Index (NDI) [41, 42], Neck Pain and Disability Scale (NPADS) [43], and Oswestry questionnaire [44]. The study by Nouri et al. [38] reports a decrease in disability assessed with WOMAC and Kujala for both study groups compared with baseline evaluation, although without statistically significant differences between groups for WOMAC in the pain, function, or stiffness domains ( $p$-values of $0.56,0.73,0.84)$, unlike the Kujala questionnaire, where the experimental group showed less disability ( $p=$ 0.053). Roberts et al. [39] observed a decrease in disability at 10 days, as well as 3,6 , and 12 weeks after treatment $(p<$ 0.001 ). Studies using NDI implied improved functionality for both groups at the end of treatment and follow-up assessments. Dundar et al. [41] reports decreased cervical disability in favour of the experimental group at 4 and 12 weeks $(p<$ 0.0001), while Venosa et al. [42] determined lower mean scores for the experimental group but without indicating statistical significance. For the NPADS, a reduction in disability was reported in both groups with respect to the evaluation at $\mathrm{TO}$, but without statistically significant differences between them [43].

Only one study uses the SF-36 questionnaire for general health assessment in physical, mental, and emotional dimensions [41]. Both groups presented an improvement for general health, with statistically significant differences between groups for all the items of the questionnaire at weeks 4 and 12 ( $p<0.0001)$, except vitality domains ( $p=0.467$ at 4 weeks; $p=0.527$ at 12 weeks) and general mental health $(p=0.854$ at 12 weeks; $p=0.613$ at 12 weeks) [41].

\section{Discussion}

The purpose of this systematic review was to investigate the scientific evidence of the last decade for effectiveness of class IV laser as an analgesic treatment in MSDs. The results suggest that this treatment may be an option for the management of pain in MSDs by reducing pain intensity and improving function.

This systematic review included 7 RCTs evaluated with low risk of bias and good methodological quality for $100 \%$ of the articles after being assessed with the Cochrane Collaboration bias tool and PEDro scale, with an average score of 9 . Overall, $57 \%$ of the articles $(n=4)$ report the use of class IV laser as treatment for spinal MSDs [41-44], while $28 \%$ $(n=2)$ describe treatment of knee conditions [38] and 14\% $(n=1)$ refer to elbow conditions [39]. Furthermore, it is observed that the main MSDs treated with laser are of joint origin $(71 \%, n=5)$ [38, 40, 42-44], followed by myofascial pain $(14 \%, n=1)$ [41] and tendinopathies $(14 \%, n=1)$ [39]. This is in line with research carried out with class Illb laser, in which systematic reviews and meta-analyses report the best results in reducing pain and improving function in joint-origin MSDs [47-49]. Favourable results observed in MSD of non-articular origin are promising and encourage us to continue developing new RCTs under these conditions. This is also supported by research conducted with LILT that verifies its use in pain management in myofascial conditions and tendinopathies [50-52].

It should be noted that $85.6 \%$ of the articles $(n=6)$ reported chronic MSDs [38-43], while in 14.4\% $(n=1)$, pain progression time was not indicated [43]. Importantly, MSDs associated with chronic pain involve more central than peripheral neural adaptation mechanisms, including possible sensitization of neurons at the medullary or thalamic level [6-9, 52, 53]. Laser applications in this systematic review were oriented to local sites, obtaining equally good analgesic results in the short and long term. Although the analgesic mechanisms of the laser are not entirely clear, they could be supported by the release of opioid peptides (beta-endorphins), whose antinociceptive effect occurs at the central and peripheral levels [16, 17, 19-25].

It is also observed that in $29 \%$ of the studies $(n=2)$, the laser was compared with a simulated application; long-term analgesic effects were observed for the comparison groups, although with more significance in favour of the experimental groups [39, 40]. This could be supported by physical rest provided to patients during the period when the studies were developed and/or by the possible placebo components of the sham treatment [54-56].

This systematic review highlights the use of VAS as the main instrument for assessing pain changes in the reported MSDs. This improves the quality of the obtained results by the evidence that supports VAS psychometric properties (reliability: 0.97; high correlation with other pain measurement instruments: Pearson's $r$ : 0.88) [45, 46, 53-55]. It should be noted that $71 \%$ of the studies $(n=5)$ applied VAS at rest and in movement [38-40, 43], and that 29\% $(n=2)$ additionally incorporated the assessment of nocturnal pain [41, 44]. This is interesting because pain changes are associated with function and activity. On the other hand, $71 \%$ of the articles $(n=5)$ reported the use of class IV laser in conjunction with other therapeutic interventions in the experimental group [38, 41-44], while 29\% $(n=2)$ applied laser alone [39, 40]. In the studies in which laser was accompanied by other intervention, therapeutic exercises (stretching, mobility, or isometric strengthening) were used in $100 \%(n=5)$, while $15 \%$ 
$(n=1)$ reported hot pack application before laser application. A statistically significant decrease in pain was observed in the experimental groups in studies in which laser accompanied other interventions, a result that could be directly attributed to lasers because control groups received the same treatment (apart from laser or sham) [38, 41-44]. It is emphasized that the selected complementary interventions also presented benefits for the MSDs treated, complying with the bioethical principle of beneficence, providing treatment for all patients, regardless of the results obtained for laser [57-60].

The most repeated secondary outcome for the RCTs was disability, assessed with different written questionnaires, including WOMAC, Kujala, NDI, and NPADS, depending on the MSD to be treated. The review of the psychometric properties of these questionnaires highlights an average sensitivity and specificity greater than 0.70 (WOMAC: sensitivity of 0.80 and specificity of 0.57 ; Kujala: sensitivity of 0.80 and specificity of 0.90 ; NDI: sensitivity of 0.78 and specificity of 0.80 ; NPADS: sensitivity of 0.74 and specificity of 0.70 ), which supports the usage of these instruments in the initial assessment of disability and changes for the follow-up evaluations after the treatment [60-66]. It is emphasized that the studies consider the assessment of disability given that one of the main problems in MSDs is the loss of functionality and physical capacity because of pain [2-3]. Although the laser therapy focused on pain management, the improvement in functionality in the short and long term is valued [38-44]. It is recommended that new trials to be conducted continue to consider functional assessment as a main outcome because it is most relevant for patients.

The articles indicate an average number of sessions between 5 and 10 to obtain favourable analgesic results for the treated MSDs. It should be stated that the conditions treated were chronic (more than 3 months of evolution) and that laser application for a few sessions already generated significant improvements in pain and function, changes that were also maintained in the long term [38-44].

Despite the fact that the results show efficacy with laser therapy, the diversity of dosages used is considered a limitation of the studies, reporting varied energy densities without specifying aspects such as chronicity of the condition, period of tissue repair, magnitude of pain, or others that the researchers considered to establish the dosage [38-44]. This issue also occurs in class IIlb laser systematic reviews [38-44].

It is essential that the protocols report the average output power used $\left(\mathrm{W}_{\text {mean }}\right)$, since it represents the real emission power and is dependent on other parameters, such as maximum power $\left(W_{\text {max }}\right)$, emission of output (continuous or pulsed), pulse frequency $(\mathrm{Hz})$, and pulse duration (microseconds or milliseconds). Knowing the average output power $\left(\mathrm{W}_{\text {mean }}\right)$ is necessary to determine treatment times from energy densities $\left(\mathrm{J} / \mathrm{cm}^{2}\right)$ that are proposed, as well as to establish the total energy $(\mathrm{J})$ delivered for each MSD treated $[17,18]$. It is suggested for new protocols to report mean powers, which will allow to establish comparisons between studies and adopt a consensus regarding the dosage. Along the same lines, it is recommended that the World Association for Laser Therapy review and approve the existing class IV laser dosages, proposing guidelines for the development of new research.

\section{Conclusions}

Class IV laser is a recent physical therapy treatment that has been proposed for pain management in MSDs. This sys- tematic review indicates that it is effective in reducing pain and improving functionality in MSDs in the short and long term. Although laser technology is more expensive, it shows better analgesic effects compared with transcutaneous electrical nerve stimulation or therapeutic ultrasound. Although the results are favourable, it is convenient to review the dosages used, reporting explicitly in the new trials the average powers used $\left(\mathrm{W}_{\text {mean }}\right)$, as well as energy densities $\left(\mathrm{J} / \mathrm{cm}^{2}\right)$ and treatment times to better clarify the total energy delivered and establish a consensus on the dose. The main MSDs treated in this review included chronic conditions of joint origin, so it is advisable to carry out new protocols in acute or chronic non-articular MP.

\section{Disclosure statement}

No author has any financial interest or received any financial benefit from this research.

\section{Conflict of interest}

The authors state no conflict of interest.

\section{References}

1. Hawker GA, Mian S, Kendzerska T, French M. Measures of adult pain: Visual Analog Scale for Pain (VAS Pain), Numeric Rating Scale for Pain (NRS Pain), McGill Pain Questionnaire (MPQ), Short-Form McGill Pain Questionnaire (SF-MPQ), Chronic Pain Grade Scale (CPGS), Short Form-36 Bodily Pain Scale (SF-36 BPS), and Measure of Intermittent and Constant Osteoarthritis Pain (ICOAP). Arthritis Care Res. 2011;63(Suppl. 11):240-252; doi: 10.1002/acr.20543.

2. Meucci RD, Fassa AG, Faria NMX. Prevalence of chronic low back pain: systematic review. Rev Saude Publica. 2015;49:1; doi: 10.1590/S0034-8910.2015049005874.

3. The impact of musculoskeletal disorders on Americans - opportunities for action. Bone and Joint Initiative USA. 2016. Available from: http://www.boneandjointburden. org/docs/BMUSExecutiveSummary2016.pdf.

4. Graven-Nielsen T, Arendt-Nielsen L. Assessment of mechanisms in localized and widespread musculoskeletal pain. Nat Rev Rheumatol. 2010;6(10):599-606; doi: 10.1038/nrrheum.2010.107.

5. Clark J, Nijs J, Yeowell G, Goodwin PC. What are the predictors of altered central pain modulation in chronic musculoskeletal pain populations? A systematic review. Pain Physician. 2017;20(6):487-500; doi: 10.36076/ ppj.2017.20.5.487.

6. Nijs J, Van Houdenhove B, Oostendorp RAB. Recognition of central sensitization in patients with musculoskeletal pain: application of pain neurophysiology in manual therapy practice. Man Ther. 2010;15(2):135-141; doi: 10.1016/j.math.2009.12.001.

7. Nijs J, van Wilgen CP, Van Oosterwijck J, van Ittersum M, Meeus M. How to explain central sensitization to patients with 'unexplained' chronic musculoskeletal pain: practice guidelines. Man Ther. 2011;16(5):413-418; doi: 10.1016/j.math.2011.04.005.

8. Fenton BW, Shih E, Zolton J. The neurobiology of pain perception in normal and persistent pain. Pain Manag. 2015;5(4):297-317; doi: 10.2217/pmt.15.27.

9. Aydede M, Shriver A. Recently introduced definition of "nociplastic pain" by the International Association for the Study of Pain needs better formulation. Pain. 2018; 159(6):1176-1177; doi: 10.1097/j.pain.000000000000 1184. 
10. Clauw DJ. Diagnosing and treating chronic musculoskeletal pain based on the underlying mechanism(s). Best Pract Res Clin Rheumatol. 2015;29(1):6-19; doi: 10.1016/j.berh.2015.04.024.

11. Laimi K, Mäkilä A, Bärlund E, Katajapuu N, Oksanen A, Seikkula V, et al. Effectiveness of myofascial release in treatment of chronic musculoskeletal pain: a systematic review. Clin Rehabil. 2018;32(4):440-450; doi: 10.1177/ 0269215517732820.

12. Jamtvedt G, Dahm KT, Christie A, Moe RH, Haavards holm E, Holm I, et al. Physical therapy interventions for patients with osteoarthritis of the knee: an overview of systematic reviews. Phys Ther. 2008;88(1):123-136; doi: 10.2522/ptj.20070043.

13. Ghaderi F, Javanshir K, Jafarabadi MA, Moghadam AN, Arab AM. Chronic neck pain and muscle activation characteristics of the shoulder complex. J Bodyw Mov Ther. 2019;23(4):913-917; doi: 10.1016/j.jbmt.2019.02.019.

14. Lesnak J, Sluka KA. Chronic non-inflammatory muscle pain: central and peripheral mediators. Curr Opin Physiol. 2019;11:67-74; doi: 10.1016/j.cophys.2019.06.006.

15. Clijsen R, Brunner A, Barbero M, Clarys P, Taeymans J. Effects of low-level laser therapy on pain in patients with musculoskeletal disorders: a systematic review and metaanalysis. Eur J Phys Rehabil Med. 2017;53(4):603-610; doi: 10.23736/S1973-9087.17.04432-X.

16. Cotler HB, Chow RT, Hamblin MR, Carroll J. The use of low level laser therapy (LLLT) for musculoskeletal pain. MOJ Orthop Rheumatol. 2015;2(5):00068; doi: 10.15406/ mojor.2015.02.00068.

17. Cameron M. Physical agents in rehabilitation. St. Louis: Elsevier; 2013.

18. Watson T. Electrotherapy: evidence-based practice [in Spanish]. Barcelona: Elsevier; 2009.

19. Khalkhal E, Razzaghi M, Rostami-Nejad M, RezaeiTavirani M, Beigvand HH, Tavirani MR. Evaluation of laser effects on the human body after laser therapy. J Lasers Med Sci. 2020;11(1):91-97; doi: 10.15171/jlms. 2020.15.

20. Karu TI. Ten lectures on basic science of laser phototherapy. Grängesberg: Prima Books; 2007.

21. Vreman HJ, Wong RJ, Stevenson DK. Phototherapy: current methods and future directions. Semin Perinatol. 2004;28(5):326-333; doi:10.1053/j.semperi.2004.09.003.

22. De Freitas LF, Hamblin MR. Proposed mechanisms of photobiomodulation or low-level light therapy. IEEE J Sel Top Quantum Electron. 2016;22(3):7000417; doi: 10.1109/JSTQE.2016.2561201.

23. Ohshiro T, Ohshiro T, Sasaki K, Kishi K. Picosecond pulse duration laser treatment for dermal melanocytosis in Asians: a retrospective review. Laser Ther. 2016;25(2): 99-104; doi: 10.5978/islsm.16-OR-07.

24. Ferraresi C, Huang Y-Y, Hamblin MR. Photobiomodulation in human muscle tissue: an advantage in sports performance? J Biophotonics. 2016;9(11-12):1273-1299; doi: 10.1002/jbio.201600176.

25. Alayat MSM, Mohamed AA, Helal OF, Khaled OA. Efficacy of high-intensity laser therapy in the treatment of chronic neck pain: a randomized double-blind placebocontrol trial. Lasers Med Sci. 2016;31(4):687-694; doi: 10.1007/s10103-016-1910-2.

26. Lopes-Martins RAB, Marcos RL, Leal-Junior ECP, Bjordal JM. Low-level laser therapy and World Association for Laser Therapy dosage recommendations in musculoskeletal disorders and injuries. Photomed Laser Surg.
27. Stiglić-Rogoznica N, Stamenković D, Frlan-Vrgoc L, Avancini-Dobrović V, Vrbanić TSL. Analgesic effect of high intensity laser therapy in knee osteoarthritis. Coll Antropol. 2001;35(Suppl. 2):183-185.

28. Mansouri V, Arjmand B, Rezaei Tavirani M, Razzaghi M, Rostami-Nejad M, Hamdieh M. Evaluation of efficacy of low-level laser therapy. J Lasers Med Sci. 2020;11(4): 369-380; doi: 10.34172/jlms.2020.60.

29. Karu T. Mitochondrial mechanisms of photobiomodulation in context of new data about multiple roles of ATP. Photomed Laser Surg. 2010;28(2):159-160; doi: 10.1089/ pho.2010.2789.

30. Kheshie AR, Alayat MSM, Ali MME. High-intensity versus low-level laser therapy in the treatment of patients with knee osteoarthritis: a randomized controlled trial. Lasers Med Sci. 2014;29(4):1371-1376; doi: 10.1007/ s10103-014-1529-0.

31. Moher D, Liberati A, Tetzlaff J, Altman DG, PRISMA Group. Preferred reporting items for systematic reviews and meta-analyses: the PRISMA statement. BMJ. 2009; 339:b2535; doi: 10.1136/bmj.b2535.

32. Van Loveren C, Aartman IHA. The PICO question [in Dutch]. Ned Tijdschr Tandheelkd. 2007;114:172-178.

33. Ouzzani M, Hammady H, Fedorowicz Z, Elmagarmid A. Rayyan - a web and mobile app for systematic reviews. Syst Rev. 2016;5(1):210; doi: 10.1186/s13643-0160384-4.

34. Maher CG, Sherrington C, Herbert RD, Moseley AM, Elkins M. Reliability of the PEDro scale for rating quality of randomized controlled trials. Phys Ther. 2003;83(8): 713-721; doi: 10.1093/ptj/83.8.713.

35. De Morton NA. The PEDro scale is a valid measure of the methodological quality of clinical trials: a demographic study. Aust J Physiother. 2009;55(2):129-133; doi: 10.1016/s0004-9514(09)70043-1.

36. Savović J, Weeks L, Sterne JAC, Turner L, Altman DG, Moher D, et al. Evaluation of the Cochrane Collaboration's tool for assessing the risk of bias in randomized trials: focus groups, online survey, proposed recommendations and their implementation. Syst Rev. 2014;3:37; doi: 10.1186/2046-4053-3-37.

37. Stovold E, Beecher D, Foxlee R, Noel-Storr A. Study flow diagrams in Cochrane systematic review updates: an adapted PRISMA flow diagram. Syst Rev. 2014;3:54; doi: 10.1186/2046-4053-3-54.

38. Nouri F, Raeissadat SA, Eliaspour D, Rayegani SM, Rahimi MS, Movahedi B. Efficacy of high-power laser in alleviating pain and improving function of patients with patellofemoral pain syndrome: a single-blind randomized controlled trial. J Lasers Med Sci. 2019;10(1): 37-43; doi: 10.15171/jlms.2019.06.

39. Roberts DB, Kruse RJ, Stoll SF. The effectiveness of therapeutic class IV (10 W) laser treatment for epicondylitis. Lasers Surg Med. 2013;45(5):311-317; doi: 10.1002/lsm.22140.

40. Angelova A, llieva EM. Effectiveness of high intensity laser therapy for reduction of pain in knee osteoarthritis. Pain Res Manag. 2016;2016:9163618; doi: 10.1155/ 2016/9163618.

41. Dundar U, Turkmen U, Toktas H, Solak O, Ulasli AM. Effect of high-intensity laser therapy in the management of myofascial pain syndrome of the trapezius: a doubleblind, placebo-controlled study. Lasers Med Sci. 2015; 30(1):325-332; doi: 10.1007/s10103-014-1671-8.

42. Venosa M, Romanini E, Padua R, Cerciello S. Comparison of high-intensity laser therapy and combination 
of ultrasound treatment and transcutaneous nerve stimulation in patients with cervical spondylosis: a randomized controlled trial. Lasers Med Sci. 2019;34(5):947953; doi: 10.1007/s10103-018-2682-7.

43. Yilmaz M, Tarakci D, Tarakci E. Comparison of high-intensity laser therapy and combination of ultrasound treatment and transcutaneous nerve stimulation on cervical pain associated with cervical disc herniation: a randomized trial. Complement Ther Med. 2020;49:102295; doi: 10.1016/j.ctim.2019.102295.

44. Kolu E, Buyukavci R, Akturk S, Eren F, Ersoy Y. Comparison of high-intensity laser therapy and combination of transcutaneous nerve stimulation and ultrasound treatment in patients with chronic lumbar radiculopathy: a randomized single-blind study. Pak J Med Sci. 2018;34(3):530-534; doi: 10.12669/pjms.343.14345.

45. Chiarotto A, Maxwell LJ, Ostelo RW, Boers M, Tugwell P, Terwee CB. Measurement properties of visual analogue scale, numeric rating scale, and pain severity subscale of the brief pain inventory in patients with low back pain: a systematic review. J Pain. 2019;20(3):245-263; doi: 10.1016/j.jpain.2018.07.009.

46. Heller GZ, Manuguerra M, Chow R. How to analyze the Visual Analogue Scale: myths, truths and clinical relevance. Scand J Pain. 2016;13:67-75; doi: 10.1016/j. sjpain.2016.06.012.

47. Stausholm MB, Naterstad IF, Joensen J, Lopes-Martins RÁB, Sæbø H, Lund H, et al. Efficacy of low-level laser therapy on pain and disability in knee osteoarthritis: systematic review and meta-analysis of randomised placebo-controlled trials. BMJOpen. 2919;9(10):e031142; doi: 10.1136/bmjopen-2019-031142.

48. Chen J, Huang Z, Ge M, Gao M. Efficacy of low-level laser therapy in the treatment of TMDs: a meta-analysis of 14 randomised controlled trials. J Oral Rehabil. 2015; 42(4):291-299; doi: 10.1111/joor.12258.

49. Chow RT, Johnson MI, Lopes-Martins RAB, Bjordal JM. Efficacy of low-level laser therapy in the management of neck pain: a systematic review and meta-analysis of randomised placebo or active-treatment controlled trials. Lancet. 2009;374(9705):1897-1908; doi: 10.1016/S01406736(09)61522-1 [erratum in: Lancet. 2010;375(9718): 894].

50. Haslerud S, Magnussen LH, Joensen J, Lopes-Martins RAB, Bjordal JM. The efficacy of low-level laser therapy for shoulder tendinopathy: a systematic review and meta-analysis of randomized controlled trials. Physiother Res Int. 2015;20(2):108-125; doi: 10.1002/pri.1606.

51. Bjordal JM, Lopes-Martins RAB, Joensen J, Couppe C, Ljunggren $A E$, Stergioulas $A$, et al. A systematic review with procedural assessments and meta-analysis of low level laser therapy in lateral elbow tendinopathy (tennis elbow). BMC Musculoskelet Disord. 2008;9:75; doi: 10.1186/1471-2474-9-75.

52. Yeh S-W, Hong C-H, Shih M-C, Tam K-W, Huang Y-H, Kuan Y-C. Low-level laser therapy for fibromyalgia: a systematic review and meta-analysis. Pain Physician. 2019; 22(3):241-254; doi: 10.36076/ppj/2019.22.241.

53. Sanzarello I, Merlini L, Rosa MA, Perrone M, Frugiuele J, Borghi R, et al. Central sensitization in chronic low back pain: a narrative review. J Back Musculoskelet Rehabil. 2016;29(4):625-633; doi: 10.3233/BMR-160685.

54. Bijur PE, Silver W, Gallagher EJ. Reliability of the visual analog scale for measurement of acute pain. Acad Emerg Med. 2001;8(12):1153-1157; doi: 10.1111/j.1553-2712. 2001.tb01132.x.
55. Serrano-Atero MS, Caballero J, Cañas A, García-Saura PL, Serrano-Álvarez C, Prieto J. Pain assessment (II) [in Spanish]. Rev Soc Esp Dolor. 2002;9(2):109-121.

56. Rossettini G, Carlino E, Testa M. Clinical relevance of contextual factors as triggers of placebo and nocebo effects in musculoskeletal pain. BMC Musculoskelet Disord. 2018;19(1):27; doi: 10.1186/s12891-018-1943-8.

57. Facci LM, Nowotny JP, Tormem F, Trevisani VFM. Effects of transcutaneous electrical nerve stimulation (TENS) and interferential currents (IFC) in patients with nonspecific chronic low back pain: randomized clinical trial. Sao Paulo Med J. 2011;129(4):206-216; doi: 10.1590/ s1516-31802011000400003.

58. Jansen MJ, Viechtbauer W, Lenssen AF, Hendriks EJM, de Bie RA. Strength training alone, exercise therapy alone, and exercise therapy with passive manual mobilisation each reduce pain and disability in people with knee osteoarthritis: a systematic review. J Physiother. 2011;57(1):11-20; doi: 10.1016/S1836-9553(11)70002-9.

59. Bartholdy C, Juhl C, Christensen R, Lund H, Zhang W, Henriksen $M$. The role of muscle strengthening in exercise therapy for knee osteoarthritis: a systematic review and meta-regression analysis of randomized trials. Semin Arthritis Rheum. 2017;47(1):9-21; doi: 10.1016/j. semarthrit.2017.03.007.

60. Coulombe BJ, Games KE, Neil ER, Eberman LE. Core stability exercise versus general exercise for chronic low back pain. J Athl Train. 2017;52(1):71-72; doi: 10.4085/ 1062-6050-51.11.16.

61. Giesinger JM, Hamilton DF, Jost B, Behrend H, Giesinger K. WOMAC, EQ-5D and Knee Society Score thresholds for treatment success after total knee arthroplasty. J Arthroplasty. 2015;30(12):2154-2158; doi: 10.1016/j. arth.2015.06.012.

62. Mustamsir E, Phatama KY, Pratianto A, Pradana AS, Sukmajaya WP, Pandiangan RAH, et al. Validity and reliability of the Indonesian version of the Kujala score for patients with patellofemoral pain syndrome. Orthop J Sports Med. 2020;8(5):2325967120922943; doi: 10.1177/ 2325967120922943.

63. MacDermid JC, Walton DM, Avery S, Blanchard A, Etruw E, McAlpine C, et al. Measurement properties of the neck disability index: a systematic review. J Orthop Sports Phys Ther. 2009;39(5):400-417; doi: 10.2519/ jospt.2009.2930.

64. Jorritsma W, Dijkstra PU, de Vries GE, Geertzen JHB, Reneman MF. Detecting relevant changes and responsiveness of Neck Pain and Disability Scale and Neck Disability Index. Eur Spine J. 2012;21(12):2550-2557; doi: 10.1007/s00586-012-2407-8.

65. Munguia FM, Jang J, Salem M, Clark GT, Enciso R. Efficacy of low-level laser therapy in the treatment of temporomandibular myofascial pain: a systematic review and meta-analysis. J Oral Facial Pain Headache. 2018;32(3): 287-297; doi: 10.11607/ofph.2032.

66. Huang Z, Ma J, Chen J, Shen B, Pei F, Kraus VB. The effectiveness of low-level laser therapy for nonspecific chronic low back pain: a systematic review and metaanalysis. Arthritis Res Ther. 2015;17:360; doi: 10.1186/ s13075-015-0882-0. 